\title{
Social Media for Informal Learning: a Case of \#Twitterstorians
}

\author{
Priya Kumar \\ Ted Rogers School of Management \\ Social Media Lab, Ryerson University \\ p1kumar@ryerson.ca
}

\author{
Anatoliy Gruzd \\ Ted Rogers School of Management \\ Social Media Lab, Ryerson University \\ gruzd@ryerson.ca
}

\begin{abstract}
Open, online environments like social media are now a mainstay of life-long informal learning. Social media like Twitter help people gather information, share resources, and discuss with other participant-learners with similar interests. This paper seeks to test and validate the 'learning in the wild' coding schema in the context of discussions on Twitter, an approach first developed for studying learning communities on Reddit. The schema considers how participant-learners are leveraging social media to facilitate self-directed informal learning practices, exploratory dialogue, and communicative exchanges. We apply the coding schema on a sample of tweets $(n=594)$ from the History Twittersphere community (\#Twitterstorians) to provide a more nuanced understanding of the different kinds of discursive practices, resource exchanges, and ideas being shared and communicated outside traditional classroom settings.
\end{abstract}

\section{Introduction}

There are many reasons that draw people to social media. Learning and teaching are prominently among them [1]-[3]. From collaborative encyclopedia projects like Wikipedia to video sharing platforms like YouTube, social media platforms have quickly become a staple for many researchers, teachers, and students interested in discovering and sharing online resources on any and every subject, topic, and event. These include resources such as podcasts, 'how to' infographics, tutorial videos, educational blogs, Massive Open Online Courses (MOOCs). In addition to discovering relevant resources, social media platforms also allow users to ask questions, discuss and debate issues, and learn through this deliberative process.

Such trends pose new challenges for scholars in elearning, open learning and learning analytics, who confront new questions about how to best capture and accurately study informal learning processes taking place on social media. Even so, much of the research in this area has focused on developing and testing coding schemas for more formal educational settings (e.g., courses, classes, workshops). Not enough research has been conducted on how to best take account of the many ways in which everyday people are using social media to engage in deliberative processes and informal learning [4], [5]. Accordingly, this paper responds to this gap by developing and evaluating mechanisms to study informal learning processes occurring in social media.

We ground our research in the analysis of an active online community of historians who are interested in connecting, communicating with and learning from one another across two commonly used social media platforms: Twitter and Reddit. The Reddit-based group (known as askHistorians) of this larger community has been the subject of a previous study [6]. In the current work, we examine how this community sustains itself on Twitter using the \#Twitterstorians hashtag, and how their information, communication and discursive practices on Twitter compares to their use of Reddit. In the context of studying informal learning among members of the \#Twitterstorians community, we ask:

RQ1: What types of information and communication exchanges and discursive practices present on Twitter?

RQ2: Does Twitter facilitate different types of information and communication exchanges and discursive practices than Reddit?

To answer these questions, we use the 'learning in the wild' coding schema to analyze a sample of Twitter posts. The coding schema was developed and validated as part of our previous work on Reddit-based learning communities. As detailed in forthcoming sections, a key strength of this coding schema is that it goes beyond the yes/no binary (e.g., "is learning occurring?"). More specifically, we posit that coding learning processes in social media requires acknowledging that communicative exchanges are often situated in a community context relative to each social media platform and its particular culture.

In the current paper we examine \#Twitterstorians, a community designed to sustain information sharing and communication among those interested in history (selfdescribed 'history buffs'). The \#Twitterstorians hashtag was first created in 2007, by Katrina Gulliver a historian 
looking to connect and communicate with others interested in historical topics inside and outside academia [7]. Speaking to its growing popularity, the American Historical Association now recommends historians join Twitter and use educational hashtags like \#Twitterstorians to participate in informal online groups and chat with other like-minded people [8].

By examining the different kinds of participant-learner dialogue and socializing in the \#Twitterstorians community, the paper reports on the applicability and utility of the 'learning in the wild' coding schema for content analysis of informal learning on Twitter. Ultimately, our goal is to further test and show the overall strength, precision, and robustness of the coding schema for other scholars who may want to study informal learning occurring in social media.

\section{Twitter}

\subsection{Platform basics}

Twitter is a popular social networking site where users can share short messages called 'tweets', retweet or reply to tweets posted by other users, or simply follow others to learn about "everything from breaking news and entertainment, to sports, politics, and everyday interests" [9]. Twitter has grown substantially since first created in 2006 and continues to maintain immense popularity as a leading microblogging social networking site with approximately 69 million monthly users in the U.S. and 267 million users spread internationally [10]. Twitter ranks $12^{\text {th }}$ in terms of total global traffic, and $8^{\text {th }}$ in the U.S. where $35 \%$ of its total users reside [11].

The microblogging social networking site is known for its brevity, however in November 2017 Twitter decided to double the character allowance per tweet from 140 characters to a 280 character limit to help promote user engagement [12]-[15]. The use of \#hashtags to index and categorize tweets by keywords is another key defining feature of the site. These short strings of text are led with a number sign, and serve as an online "bookmark of content" [16] for community members to unite and connect based on similar thematic interests. Members can click hashtagged words in any tweets to find related tweets that have used the same hashtag [17].

\subsection{Hashtag communities}

Building from past scholarships, we can understand hashtags as key contributors to Twitter-based communities of practice (CoP) [18]-[20], where users connect based on shared identities, activities, and concerns; comprise community like structures through joint interactions and relationships; and participate in shared practices such as information seeking and resource sharing. Different types of hashtagged CoPs have emerged on Twitter, including those formed around discussions on politics in Canada [21], [22], the U.S. [23], [24], the U.K. [25], [26], Spain [27] and many other countries; on pressing societal issues such as environmental degradation, climate change, and the treatment of marginalized groups [28]-[30]; on healthrelated topics [31]-[35], as well as on education [36][38], to name a few examples.

In our research, we are interested in studying how hashtags afford people the capability to participate in various $\mathrm{CoPs}$ and engage in life-long and life-wide learning processes asynchronously across time and space.

\subsection{Using Twitter for teaching}

That Twitter supports multi-modal learning environments and collaborative opportunities for instructor-to-instructor, instructor-to-learner, and learnerto-learner engagements has been well-documented. For example, Twitter has been shown to enrich teaching and learning practices through dynamic processes of communication, course moderation and assessment, and professional development opportunities [39], [40], [41], [42]. Scholars like Reed have delved into what is called the '3Cs of Twitter: Community, Communication, and Causal (informal) learning' to show that individual students can indeed use the platform to develop personal learning environments (PLEs) [43].

From the perspective of instructors, Twitter presents a rich and open online environment to enhance teaching pedagogies and individual learning objectives inside and outside formal classroom settings. For example, when instructors participate on Twitter they are not focused solely on formal instruction. Rather, they tend to use the platform to share resources with their professional networks, share information about classroom affairs, request help and assistance from others, engage in social commentary, conversations, and connect with others outside of their networks [44], [45].

We note that most of the research to date has focused almost entirely on learning processes occurring in formal educational settings with student cohorts (e.g., courses, classes, workshops, conferences). However, Twitterbased communities are often loosely structured and support a multiplicity of learning processes [46], [47] that extend beyond formal education settings and studentlearner populations.

\subsection{Studying learning on Twitter}

While acknowledging the utility of social media such as Twitter in promoting asynchronous modes of communication and collaboration, we also recognize that observing informal learning processes in open, online environments require more refined and precise mechanisms of learner dialogue evaluation. Moving beyond the yes/no binary, we cannot assume that all Twitter conversations and interactions lead to learning processes. One way to delve into the discursive norms and 
practices of online hashtag communities is to rely on coding schemas for content analysis. This section will review content analysis schemas that can help identify learning processes based on transcripts of text-based discussions.

Pena-Shaff and Nicholls developed a coding schema to analyze participation in Bulletin Board discussions, finding collaborative reflection messages in the form of clarification, elaboration, and interpretation were most conducive to knowledge construction processes among students [48]. This coding application highlights that participant-learners in closed-learning environments engage in meaning-making and knowledge construction through both positive (agreement) and negative (disagreement) communicative text-based exchanges.

De Laat and Lally [49] used two complementary coding schemas [50], [51] to uncover learning and tutoring processes occurring in messages exchanged by Master's students in a learning management system. Their research found that while individuals behave differently in learning communities, they exhibit similar participation patterns, with some assuming a conversational facilitator role and others offering limited support to group collaborations.

Baker, Andriessen, Lund, van Amelsvoort, and Quignard [52] developed the 'Rainbow' coding framework, in which colors are used to categorize and visualize different task focused and non-task focused activities transpiring in a computer-supported collaborative learning environment called DREW. The authors use the schema to elaborate on the phases of deliberation and argumentation in student-learning by showing that conversational debates can help broaden and deepen knowledge construction.

Weinberger and Fischer [53] applied a multidimensional coding framework to discourse corpora collected from experimental online learning environments with discussion boards, and found that argumentative dimensions of collaborative learning feed social modes of knowledge co-construction (e.g., conflict-orientated consensus building).

In sum, much of the work in this area has focused on developing content analysis schemas for closed environments where conversations between participants follow more defined schedules, and only include classbased participants. The difference in our research is that we seek to examine informal learning processes occurring in social media that may not be present in closed-learning environments, formal classrooms, or include formal instructors.

Moving from the confines of the classroom, we turn to the 'learning in the wild' coding schema developed to study different informal learning processes occurring in social media (Table 1). This coding schema expands on the work of Mercer [54], Buckingham Shum, Ferguson, and colleagues [55], and considers exploratory dialogue and talk to be essential features of collaborative learning and knowledge construction processes in open, online environments. The 8-item coding schema was designed to capture subtle nuances in the ways people interact, provide explanations (positive and negative), socialize, engage in Q\&A transactions, all of which support collaborative engagements and self-directed learning practices. Previous research has shown the utility and applicability of the coding schema when analyzing unstructured, informal learning on Reddit, across four different 'Ask' subreddit communities ('askHistorians', 'Ask_Politics', 'askscience', AskAcademia') [6]. The broad objective of the current research therefore is to further test and validate this coding schema for content analysis on another social media platform, on Twitter.

Table 1. 'Learning in the Wild' Coding Schema

\begin{tabular}{|c|c|c|}
\hline Code & Definition & $\begin{array}{l}\text { Linguistic } \\
\text { Dialogue Example }\end{array}$ \\
\hline $\begin{array}{l}\text { 1. Explanation } \\
\text { with } \\
\text { Disagreement }\end{array}$ & $\begin{array}{l}\text { Expresses a NEGATIVE } \\
\text { take on the content of the } \\
\text { previous posts by adding } \\
\text { new ideas or facts to } \\
\text { discussion thread }\end{array}$ & $\begin{array}{l}\text { 'But', 'I disagree', } \\
\text { 'not sure', 'not } \\
\text { exactly' with } \\
\text { explanation/ } \\
\text { judgement/ } \\
\text { reasoning/ etc. }\end{array}$ \\
\hline $\begin{array}{l}\text { 2. Explanation } \\
\text { with } \\
\text { Agreement }\end{array}$ & $\begin{array}{l}\text { Expresses a POSITIVE } \\
\text { take on the content of the } \\
\text { previous posts by adding } \\
\text { new ideas or facts to } \\
\text { discussion thread }\end{array}$ & $\begin{array}{l}\text { 'Indeed', 'also', 'I } \\
\text { agree', with } \\
\text { explanation/ } \\
\text { judgement/ } \\
\text { reasoning/ etc. }\end{array}$ \\
\hline $\begin{array}{l}\text { 3. Explanation } \\
\text { with Neutral } \\
\text { Presentation }\end{array}$ & $\begin{array}{l}\text { Expresses a NEUTRAL } \\
\text { explanation/judgement/re } \\
\text { asoning/etc. with neither } \\
\text { negative nor positive } \\
\text { reference to the content } \\
\text { of the previous posts, nor } \\
\text { necessarily any reference } \\
\text { to previous posts }\end{array}$ & $\begin{array}{l}\text { 'I can understand', } \\
\text { 'interesting', } \\
\text { 'depends on...' or } \\
\text { statement responses }\end{array}$ \\
\hline $\begin{array}{l}\text { 4. Socializing } \\
\text { with Negative } \\
\text { Intent }\end{array}$ & $\begin{array}{l}\text { Socializing that } \\
\text { expresses negative affect } \\
\text { through tone, words, } \\
\text { insults, expletives } \\
\text { intended as abusive }\end{array}$ & $\begin{array}{l}\text { 'no', 'you're an } \\
\text { idiot', 'this has } \\
\text { been explained } \\
\text { multiple times' }\end{array}$ \\
\hline $\begin{array}{l}\text { 5. Socializing } \\
\text { with Positive } \\
\text { Intent }\end{array}$ & $\begin{array}{l}\text { Socializing that } \\
\text { expresses positive affect } \\
\text { tone, words, praise, } \\
\text { humour, irony intended } \\
\text { in a positive way }\end{array}$ & $\begin{array}{l}\text { 'thanks', 'great } \\
\text { feedback', 'you're } \\
\text { correct' }\end{array}$ \\
\hline $\begin{array}{l}\text { 6. Information } \\
\text { Seeking }\end{array}$ & $\begin{array}{l}\text { Postings asking } \\
\text { questions or soliciting } \\
\text { opinions, resources, etc. } \\
\text { This does not include } \\
\text { questions answered } \\
\text { rhetorically within the } \\
\text { post, e.g., if a question is } \\
\text { asked and answered }\end{array}$ & $\begin{array}{l}\text { 'First you have to } \\
\text { think what happens } \\
\text { if ...?' and then you } \\
\text { can see what } \\
\text { happens', 'does } \\
\text { anyone know', 'can } \\
\text { anyone explain' }\end{array}$ \\
\hline
\end{tabular}




\begin{tabular}{|l|l|l|}
\hline $\begin{array}{l}\text { 7. Providing } \\
\text { Resource }\end{array}$ & $\begin{array}{l}\text { Postings that include } \\
\text { direct reference to a } \\
\text { URL, book, article, etc.; } \\
\text { postings that call upon a } \\
\text { well-known theory or the } \\
\text { name of a well-known } \\
\text { figure }\end{array}$ & $\begin{array}{l}\text { Link to resource } \\
\text { copied to post } \\
\text { (book, URL, article, } \\
\text { audio/video file) } \\
\text { Referencing } \\
\text { theory/theorists, } \\
\text { scholar or public } \\
\text { work (Einstein, } \\
\text { Newton, Freud) }\end{array}$ \\
\hline $\begin{array}{l}\text { 8. Rules and } \\
\text { Norms }\end{array}$ & $\begin{array}{l}\text { Postings on topics such } \\
\text { as what is the appropriate } \\
\text { for a particular } \\
\text { discussion, what } \\
\text { language is appropriate } \\
\text { to use, how to back up } \\
\text { claims by using } \\
\text { resources, using hashtags } \\
\text { etc. }\end{array}$ & $\begin{array}{l}\text { 'See/don't forget } \\
\text { link', 'this post } \\
\text { doesn't belong } \\
\text { here', } \\
\text { acknowledging } \\
\text { OP/HT Twitter } \\
\text { users, hashtags and } \\
\text { bots }\end{array}$ \\
\hline
\end{tabular}

\section{Methodology}

Using Netlytic, an online program for social media text and network analysis [56], we automatically captured all publicly available \#Twitterstorians tweets (original posts and replies) over a 30-day period from June 20-July 20, 2017. A total of 17,391 Twitter messages were collected, and after removing duplicates and retweets (referred to as 'RTs'), comprised a dataset of 6,349 tweets. We then used $10 \%$ of these tweets by selecting every $10^{\text {th }}$ tweet when sorted chronologically to create a sample of 634 tweets that were subsequently coded using the 'learning in the wild' coding schema. The manual coding was done by two independent coders, one post-doctoral fellow and one graduate research assistant who completed a schema tutorial training-module prior to commencing the coding process. 40 tweets were removed from the initial sample of 634 tweets (final sample size $n=594$ ) because they did not fit any of the pre-existing schema codes.

Results from our \#Twitterstorians coding schema showed an acceptable level of agreement between the two coders: Krippendorff's alpha of 0.65 and the intercoder agreement of $73 \%$. The resulting alpha of 0.65 is close to a recommended threshold of 0.667 to be considered reliable enough for exploratory studies like ours [57][59]. These results fall in line with previous applications of the 'learning in the wild' coding schema across four diverse 'Ask' subreddit communities on Reddit ${ }^{1}$. The results are also in line with Ferguson et al.'s [55] binary coding of online conference dialogue (exploratory and non-exploratory) which recorded an inter-annotator agreement score of 0.597, indicating 'moderate agreement' enough to train an automated classifier. At the same time, because our coding schema is not binary, and allows for a maximum of three codes per post, a lower agreement among coders would be expected.

In the final stage of the study, we compared our Twitter findings with the previous results of coding Reddit comments from the 'askHistorians' Reddit group $(n=1227)$.

\section{Results}

RQ1: What types of information and communication exchanges and discursive practices present on Twitter?

The overall results of our coding show that online conversations in the \#Twitterstorians hashtag community connect people with active knowledge building processes through an online learning environment that nurtures Q\&A interactions. Table 2 provides a detailed breakdown of coding distribution results. Percentages add up to over $100 \%$ because coders could apply up to three codes per tweet. Tweets were classified under a particular schema code only if the two coders agreed and percentages are rounded to the nearest $1 \%$. The distribution results demonstrate a higher proportion of learning material posts, with the majority of tweets coded as resource sharing and information seeking (see code 6 and 7) to and from the wider \#Twitterstorians community.

Table 2. Coding Results: \#Twitterstorians ( $n=594)$ vs Reddit's askHistorians $(\mathrm{n}=1227)$ *

\begin{tabular}{|l|l|l|}
\hline & Twitter & Reddit \\
\hline $\begin{array}{l}\text { 1. Explanation with } \\
\text { Disagreement }\end{array}$ & $3(1 \%)$ & $71(6 \%)$ \\
\hline $\begin{array}{l}\text { 2. Explanation with } \\
\text { Agreement }\end{array}$ & $4(1 \%)$ & $45(4 \%)$ \\
\hline $\begin{array}{l}\text { 3. Explanation with } \\
\text { Neutral Presentation }\end{array}$ & $73(12 \%)$ & $592(48 \%)$ \\
\hline $\begin{array}{l}\text { 4. Socializing with } \\
\text { Negative Intent }\end{array}$ & $1(0 \%)$ & $4(0 \%)$ \\
\hline $\begin{array}{l}\text { 5. Socializing with } \\
\text { Positive Intent }\end{array}$ & $99(17 \%)$ & $204(17 \%)$ \\
\hline 6. Information Seeking & $100(17 \%)$ & $274(22 \%)$ \\
\hline 7. Providing Resource & $223(38 \%)$ & $260(21 \%)$ \\
\hline 8. Rules and Norms & $22(4 \%)$ & $66(5 \%)$ \\
\hline Krippendorff's Alpha & $0.65(73 \%)$ & $0.76(79 \%)$ \\
\hline $\begin{array}{l}\text { * Messages were classified under a particular code only if } \\
\text { the two coders agreed. Percentages add up to over 100\% } \\
\text { because coders were allowed to assign up to three codes } \\
\text { per message. Percentages are rounded to the nearest 1\%. }\end{array}$ \\
\hline
\end{tabular}

Taking from our dataset, Figure 1 gives an example of observed information seeking behavior (code 6). It demonstrates how participants in this community use the \#Twitterstorians hashtag to connect with others who

\footnotetext{
1 Results from our 2016 'Ask' subreddit 'learning in the wild' coding: ask_Politics 0.60 (72\% agreement), askAcademia 0.64 (77\% agreement), askscience 0.69 (78\% agreement), askHistorians 0.76 (79\% agreement).
} 
might have the knowledge or resources to help clarify or answer questions.

\section{Figure 1. Code 6 Information Seeking}

Do I know anyone who knows anyone who
knows about the Common Fisheries Policy?
Specifically its impact on UK in 1970s?

Figure 2 presents an example of resource sharing behavior (code 7). Here, in addition to sharing an online resource (essay) with other members of the \#Twitterstorians, the user relied on Twitter's \#hashtag and @ tagging functions to share the resource with those outside the \#Twitterstorians community.

\section{Figure 2. Code 7 Providing Resource}

tinyurl.com/y9cu3dj9 Essay on \#Oregon \&
\#CivilWar from my days at the @oulibraries \&
@oregondigcol. \#amwest \#ushistory
\#twitterstorians

The coding distribution results also show a notable proportion of neutral explanations being put forth by participants. Figure 3 provides an example of an explanation with neutral presentation (code 3) and highlights the lack of emotional cues being used to shed light on a key historical event. One possible reason for this may be Twitter's culture of brevity and shorter posts. With a relatively low character limit per post, members of the \#Twitterstorians community might find it more taxing to fully explain why they agree or disagree with what other users are posting (see: code 1 and code $2=1 \%$ each). This result might also be due to our methodological decision to select every $10^{\text {th }}$ tweet for coding, neglecting chronological threaded conversations.

\section{Figure 3. Code 3 Explanation with Neutral Presentation}

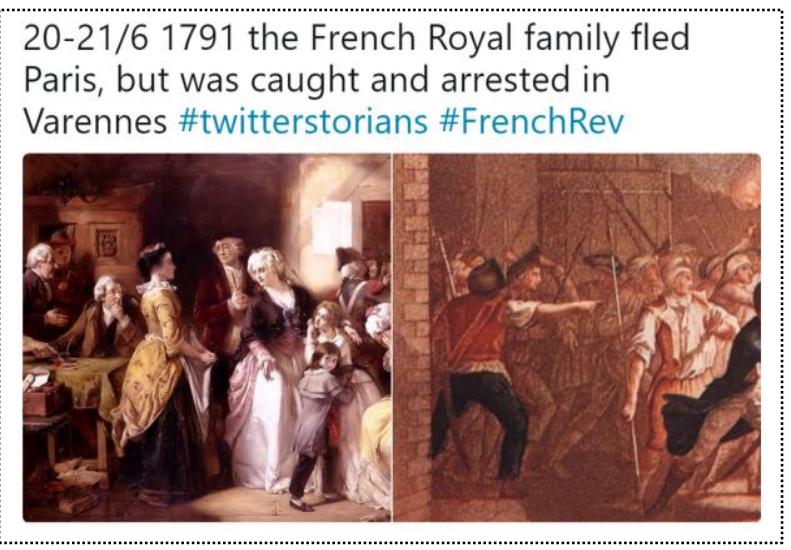

Speaking to participant-learner motivations, we also observed an overriding dominance of positive communication and socializing (e.g., 'thank you', 'excellent resource', 'great seeing you') compared to negative commentary/argumentative discourse. Specifically, our results show \#Twitterstorians conversations are far more positive (code $5=17 \%$ ) than negative (code $4=0 \%$ ) in tone. Figure 4 presents an example of positive socializing and gratitude being expressed from one \#Twitterstorians member to another (code 5).

Positive and shorter dialogue might encourage participants and 'lurkers' to engage with one another and build a stronger online community. By contrast negative conversations and hostile exchanges may silence users from wanting to explore and participate in online historical conversations, which could ultimately thwart learner dialogue among community members. This result confirms our expectation that content analysis coding schemas for learner conversations in social media must be designed to capture the humanistic elements of socializing.

\section{Figure 4. Code 5 Socializing with Positive Intent}

\#twitterstorians on the road: great meeting
@AndreaLTurpin IRL while we're both in town
on \#wmnhist business!

Finally, community members found to engage in significant boundary-maintenance activities, which in this context means following implicit community rules and norms (code 8) such as retweeting a 'history' specific post with a history specific hashtag such as \#Twitterstorians. Figure 5 provides an example of code 8 rules and norms, where a member is using the \#Twitterstorians hashtag to reorient, draw attention to, and promote an 'external' resource (a job posting) for the benefit of fellow community members.

\section{Figure 5. Code 8 Rules and Norms}

\section{\#twitterstorians}

Lecturer (Assistant Professon) in Modern Chinese History / History of Modem SE Asia at Uni of Southampton jobs acukfjob/BBU67S/lec... "jobsacuk

RQ2: Does Twitter facilitate different types of information and communication exchanges and discursive practices than Reddit?

Cross-comparison with our 2016 Reddit 'askHistorians' coding distributions results (Table 2) reveal key similarities and differences in the ways participant-learners use social media to teach, learn and collaborate in each case. Both \#Twitterstorians and 
'askHistorians' exhibit a comparatively higher proportion of neutral explanations. We also note that community dialogue is transactional and functional (code 6 and 7: Q\&A exchanges) in nature on both platforms. Coding distribution results show an overall lack of negative socializing, which suggests that both of these online platforms are supporting socially positive learner conversations despite the fact that Reddit is a predominantly anonymous environment (code 5 above $15 \%$ in both cases). This also suggests that both platforms support active historian communities, where members connect based on similar interests or goals, and strive to learn from one another across popular social media.

At the same time, the results show a higher proportion of resource sharing posts in the \#Twitterstorians dataset (Table 2, code 6: 38\%) compared to the 2016 'askHistorians' results (Table 2, code 6: 21\%). We attribute this variance to the brevity and sharing culture of Twitter, where participants push content outward and favour transactional exchanges in the form of links and audio/visual resources as opposed to more in-depth conversations on Reddit.

Platform interface design may also explain the differences in discursive practices and learning behaviors observed. There are striking differences between Twitter and Reddit platform affordances that shape the opportunities and motivations for participation. For example, our coding results show that learning through 'askHistorians' exhibits a higher proportion of posts with all three types of explanation (with disagreement, agreement, and neutral presentation). Reddit's text limit per post (over 15,000 characters) offers but one potential explanation for this result. Compared to Twitter, Reddit may be more inviting for participants looking to ask indepth questions, and/or thoroughly explain their thoughts about a particular issue with fellow community members [60]. Furthermore, the anonymity of the Reddit platform promotes blind 'peer review' through its upvote/downvote system, rewarding Redditors based on the quality of their posts (known as 'karma') which might entice members to put forth well-thought out commentary. Finally, differing from Twitter, each subreddit community is maintained by a group of moderators that administer a unique set of rules and norms that function as a code of conduct (known as 'Reddiquette') for community members to follow [61].

By contrast, the Twitter platform promotes much shorter (under 280 characters) and more public forms of conversational dialogue between participants [62]. Hashtags like \#Twitterstorians are therefore used to bind and connect individual users and help to maintain a sense of community between an otherwise dispersed network of individuals. We can for these reasons expect deliberative processes and exploratory learner dialogue on Twitter to be more 'to the point' where resources and information are easy to follow, digest, and share (code 6 and 7). At the same time, as we observed in the case of \#Twitterstorians, people can and, often choose to link conversations happening on social media to other platforms like Reddit for the benefit of wider audiences.

Hashtags like \#Twitterstorians allow members to cut through the 'noise' of Twitter, and more succinctly and strategically engage in information exchanges and exploratory dialogue with fellow members. We note for example that Twitter provides its members with access to a more 'spread-out' landscape of social networks; nurturing higher levels of bridging social capital and opportunities to connect with loose social ties [63]. More comparative work is required to confirm previous assertions that online communities supported by Twitter inherently favour information sharing behaviors over reciprocal connections between participants [64].

\section{Conclusions}

In this work, we analyzed the Twitter-based \#Twitterstorians community to understand and assess the different types of collaborative knowledge construction and discursive practices being supported by informal learning communities in social media. We applied the 'learning in the wild' coding schema to examine a sample of public tweets posted by this community. By doing so, we tested if this coding schema can reliably capture the discourse, talk, and social cues that promote exploratory dialogue in open, informal learning settings like Twitter. We used two independent coders to further apply and validate the schema and recorded an intercoder agreement of $73 \%$. Our results show that Twitter is affording new networked opportunities for participant-learners outside formal educational settings. More specially, we found that the \#Twitterstorians community sustains itself through socially positive information and resource exchanges. Short 'to the point' communicative exchanges were not as pronounced in the case of Reddit, which exhibited a greater proportion of reflective (positive and negative) indepth explanations.

Ultimately, this paper has demonstrated the strength and utility of the non-binary 'learning in the wild' coding schema when studying and evaluating informal learning on Twitter. We intend to expand this research, first by applying and further validating the schema across other social media platforms (Facebook, Instagram, LinkedIn), and then by inviting instructors who use social media like Twitter for teaching to test the schema out in order to more precisely evaluate the collaborative practices and informal socializing that increasingly play a role in both formal and informal learning environments. Lastly, our future work includes applying a machine learning approach to automate the process of coding large volume of public tweets and other types of posts to address the scalability 
issue commonly associated with the analysis of datasets from open learning environments.

\section{Acknowledgments}

This work is supported by a Social Sciences and Humanities Research Council of Canada (SSHRC) grant, "Learning Analytics for the Social Media Age", PIs: Anatoliy Gruzd and Caroline Haythornthwaite. The authors would like to thank Lilach Dahoah Halevi who helped with the manual coding of tweets and provided feedback on various drafts of this paper. We would also like to thank anonymous reviewers for providing very helpful comments during the peer review process.

\section{References}

[1] M. Esteve Del Valle, A. Gruzd, C. Haythornthwaite, D. Paulin, and S. Gilbert, "Social Media in Educational Practice: Faculty Present and Future Use of Social Media in Teaching," Hawaii Int. Conf. Syst. Sci. 2017 HICSS-50, Jan. 2017.

[2] A. Gruzd, C. Haythornthwaite, D. Paulin, S. Gilbert, and M. E. del Valle, "Uses and Gratifications factors for social media use in teaching: Instructors' perspectives," New Media Soc., vol. 20, no. 2, pp. 475-494, Feb. 2018.

[3] R. Collins and A. Gruzd, "Learning within Digital Media: Investigating the Relationships Between Student Citation Networks, Assignment Structures, and Learning Outcomes," Hawaii Int. Conf. Syst. Sci. 2017 HICSS-50, Jan. 2017.

[4] K. Verbert et al., "Learning dashboards: an overview and future research opportunities," Pers. Ubiquitous Comput., vol. 18, no. 6, pp. 14991514, 2014.

[5] B. De Wever, T. Schellens, M. Valcke, and H. Van Keer, "Content analysis schemes to analyze transcripts of online asynchronous discussion groups: A review," Comput. Educ., vol. 46, no. 1, pp. 6-28, Jan. 2006.

[6] P. Kumar, A. Gruzd, C. Haythornthwaite, S. Gilbert, M. Esteve Del Valle, and D. Paulin, "Learning in the Wild: Coding Reddit for Learning and Practice," in Proceedings of the 51st Hawaii International Conference on System Sciences, 2018.

[7] A. S. Collie, "Why Historians Should Use Twitter: An Interview with Katrina Gulliver," History News Network. [Online]. Available: https://historynewsnetwork.org/article/158669. [Accessed: 30-May-2018].

[8] "Five Ways for Historians to Use Twitter," American Historical Association, 16-Aug-2011. .

[9] "Getting Started." [Online]. Available: https://help.twitter.com/en/twitter-guide. [Accessed: 23-May-2018].
[10] D. Rushe, "Twitter reports profit for second quarter in a row and adds $6 \mathrm{~m}$ new users," The Guardian, 25-Apr-2018.

[11] "Twitter.com Traffic, Demographics and Competitors - Alexa." [Online]. Available: https://www.alexa.com/siteinfo/twitter.com. [Accessed: 23-May-2018].

[12] "Twitter doubles tweet length to 280 characters."

[13] N. Evershed, "Here's how Twitter should do longer text, and it doesn't take 280 characters," The Guardian, 08-Nov-2017.

[14] J. Kastrenakes, "Twitter says people are tweeting more, but not longer, with 280-character limit," The Verge, 08-Feb-2018. [Online]. Available: https://www.theverge.com/2018/2/8/16990308/twi tter-280-character-tweet-length. [Accessed: 23May-2018].

[15] K. Gligorić, A. Anderson, and R. West, "How Constraints Affect Content: The Case of Twitter's Switch from 140 to 280 Characters," ArXiv180402318 Cs, Apr. 2018.

[16] L. Yang, T. Sun, M. Zhang, and Q. Mei, "We Know What@You \#Tag: Does the Dual Role Affect Hashtag Adoption?," in Proceedings of the 21st International Conference on World Wide Web, New York, NY, USA, 2012, pp. 261-270.

[17] "How to use hashtags." [Online]. Available: https://help.twitter.com/en/using-twitter/how-touse-hashtags. [Accessed: 23-May-2018].

[18] C. N. Gunawardena, M. B. Hermans, D. Sanchez, C. Richmond, M. Bohley, and R. Tuttle, "A theoretical framework for building online communities of practice with social networking tools," Educ. Media Int., vol. 46, no. 1, pp. 3-16, 2009.

[19] J. Lave and E. Wenger, Situated Learning: Legitimate Peripheral Participation. Cambridge, UK: Cambridge University Press, 1991.

[20] E. Wenger, "Communities of Practice and Social Learning Systems," Organization, vol. 7, no. 2, pp. 225-246, May 2000.

[21] A. Gruzd and J. Roy, "Investigating Political Polarization on Twitter: A Canadian Perspective," Policy Internet, vol. 6, no. 1, pp. 28-45, Mar. 2014.

[22] F. McKelvey and E. Dubois, "Computational Propaganda in Canada: The Use of Political Bots," p. 32.

[23] P. N. Howard, B. Kollanyi, S. Bradshaw, and L.M. Neudert, "Social Media, News and Political Information during the US Election: Was Polarizing Content Concentrated in Swing States?," ArXiv180203573 Cs, Feb. 2018.

[24] K. Garimella and I. Weber, "A Long-Term Analysis of Polarization on Twitter," ArXiv170302769 Cs, Mar. 2017. 
[25] M. Grčar, D. Cherepnalkoski, I. Mozetič, and P. K. Novak, "Stance and influence of Twitter users regarding the Brexit referendum," Comput. Soc. Netw., vol. 4, no. 1, p. 6, Dec. 2017.

[26] A. Khatua and A. Khatua, "Leave or Remain? Deciphering Brexit Deliberations on Twitter," in 2016 IEEE 16th International Conference on Data Mining Workshops (ICDMW), 2016, pp. 428-433.

[27] R. Borge Bravo and M. Esteve Del Valle, "Political Polarisation and Network Leaderships in the Catalan Parliamentarians' Twitter Network," IDP Rev. Internet Derecho Política, vol. 0, no. 20, Jul. 2015.

[28] B. White, H. Castleden, and A. Gruzd, "Talking to Twitter users: Motivations behind Twitter use on the Alberta oil sands and the Northern Gateway Pipeline," First Monday, vol. 20, no. 1, Dec. 2014.

[29] A. Segerberg and W. L. Bennett, "Social Media and the Organization of Collective Action: Using Twitter to Explore the Ecologies of Two Climate Change Protests," Commun. Rev., vol. 14, no. 3, pp. 197-215, 2011.

[30] D. Moscato, "Media Portrayals of Hashtag Activism: A Framing Analysis of Canada's \#Idlenomore Movement," Media Commun., vol. 4, no. 2, pp. 3-12, Apr. 2016.

[31] W. W. Xu, I.-H. Chiu, Y. Chen, and T. Mukherjee, "Twitter hashtags for health: applying network and content analyses to understand the health knowledge sharing in a Twitter-based community of practice," Qual. Quant., vol. 49, no. 4, pp. 1361-1380, Jul. 2015.

[32] N. Pemmaraju, V. Gupta, R. Mesa, and M. Thompson, "Social Media and Myeloproliferative Neoplasms (MPN)_Focus on Twitter and the Development of a Disease-specific Community: \#MPNSM," Curr. Hematol. Malig. Rep., vol. 10, no. 4, pp. 413-420, 2015.

[33] E. A. Krueger and S. D. Young, "Twitter: A Novel Tool for Studying the Health and Social Needs of Transgender Communities," JMIR Ment. Health, vol. 2, no. 2, May 2015.

[34] S. Gilbert, "Learning in a Twitter-based community of practice: an exploration of knowledge exchange as a motivation for participation in \#hcsmca," Inf. Commun. Soc., vol. 19, no. 9, pp. 1214-1232, Sep. 2016.

[35] A. Gruzd and C. Haythornthwaite, "Enabling Community Through Social Media," J. Med. Internet Res., vol. 15, no. 10, p. e248, Oct. 2013.

[36] A. Gruzd, D. Paulin, and C. Haythornthwaite, "Analyzing Social Media and Learning through Content and Social Network Analysis: A Faceted Methodological Approach,” J. Learn. Anal., vol. 3, no. 3, pp. 46-71, 2016.
[37] V. G. Britt and T. Paulus, "Beyond the Four Walls of My Building': A Case Study of \#Edchat as a Community of Practice," Am. J. Distance Educ., vol. 30, no. 1, pp. 48-59, 2016.

[38] P. Wesely, "Investigating the Community of Practice of World Language Educators on Twitter," J. Teach. Educ., vol. 64, no. 4, pp. 305318, 2013.

[39] G. Tur, V. I. Marín, and J. Carpenter, "Using Twitter in Higher Education in Spain and the USA," Uso Twitter En Educ. Super. En Esp. E. U., vol. 25, no. 51, pp. 19-27, 4/1/2017 2017.

[40] L. Sharp, "Twitter as a Technology Tool to Elicit Deeper Levels of Understanding among Adult Learners," J. Lit. Technol., vol. 18, no. 3, pp. 5684, 2017.

[41] E. Kassens-Noor, "Twitter as a teaching practice to enhance active and informal learning in higher education: The case of sustainable tweets," Act. Learn. High. Educ., vol. 13, no. 1, pp. 9-21, 2012.

[42] C. Haythornthwaite, "Social Networks and Learning Networks: Using social network perspectives to understand social learning," Networked Learn., p. 8, 2010.

[43] P. Reed, "Hashtags and retweets: using Twitter to aid Community, Communication and Casual (informal) learning," Res. Learn. Technol., vol. 21, no. $1,2013$.

[44] G. Veletsianos, "Higher education scholars' participation and practices on Twitter," J. Comput. Assist. Learn., vol. 28, no. 4, pp. 336-349, 2012.

[45] B. Lewis and D. Rush, "Experience of developing Twitter-based communities of practice in higher education," Res. Learn. Technol., vol. 21, no. 1, 2013.

[46] M. M. Wasko, R. Teigland, and S. Faraj, "The provision of online public goods: Examining social structure in an electronic network of practice," Decis. Support Syst., vol. 47, no. 3, pp. 254-265, 2009.

[47] J. S. Brown and P. Duguid, "Knowledge and Organization: A Social-Practice Perspective," Organ. Sci., vol. 12, no. 2, pp. 198-213, Apr. 2001.

[48] J. B. Pena-Shaff and C. Nicholls, "Analyzing student interactions and meaning construction in computer bulletin board discussions," Comput. Educ., vol. 42, no. 3, pp. 243-265, Apr. 2004.

[49] M. D. Laat and V. Lally, "Complexity, theory and praxis: Researching collaborative learning and tutoring processes in a networked learning community," Instr. Sci., vol. 31, no. 1-2, pp. 7-39, Jan. 2003.

[50] T. Anderson, L. Rourke, D. R. Garrison, and W. Archer, "Assessing teaching presence in a 
computer conferencing context," J. Asynchronous Learn. Netw., pp. 1-17, 2001.

[51] A. E. Veldhuis-Diermanse, "CSCLearning?: participation, learning activities and knowledge construction in computer-supported collaborative learning in higher education," s.n.], S.1., 2002.

[52] M. Baker, J. Andriessen, K. Lund, M. Amelsvoort, and M. Quignard, "Rainbow: A framework for analysing computer-mediated pedagogical debates," Int. J. Comput.-Support. Collab. Learn., vol. 2, no. 2-3, pp. 315-357, 2007.

[53] A. Weinberger and F. Fischer, "A framework to analyze argumentative knowledge construction in computer-supported collaborative learning," Comput. Educ., vol. 46, no. 1, pp. 71-95, 2006.

[54] N. Mercer, "Sociocultural discourse analysis: analysing classroom talk as a social mode of thinking," J. Appl. Linguist., vol. 1, no. 2, pp. 137168, Aug. 2004.

[55] R. Ferguson, Z. Wei, Y. He, and S. Buckingham Shum, "An Evaluation of Learning Analytics to Identify Exploratory Dialogue in Online Discussions," in Proceedings of the Third International Conference on Learning Analytics and Knowledge, New York, NY, USA, 2013, pp. 85-93.

[56] "Netlytic - social media text and social networks analyzer." [Online]. Available: https://netlytic.org/. [Accessed: 30-May-2018].

[57] M. Bolognesi, R. Pilgram, and R. van den Heerik, "Reliability in content analysis: The case of semantic feature norms classification," Behav. Res. Methods, vol. 49, no. 6, pp. 1984-2001, Dec. 2017.

[58] A. F. Hayes and K. Krippendorff, "Answering the Call for a Standard Reliability Measure for Coding Data," Commun. Methods Meas., vol. 1, no. 1, pp. 77-89, 2007.

[59] K. Krippendorff, "Reliability in Content Analysis," Hum. Commun. Res., vol. 30, no. 3, pp. 411-433, 2004.

[60] C. Haythornthwaite, P. Kumar, A. Gruzd, S. Gilbert, M. E. del Valle, and D. Paulin, "Learning in the wild: coding for learning and practice on Reddit," Learn. Media Technol., vol. 43, no. 3, pp. 219-235, Jul. 2018.

[61] M. Loudon, "'Research in the wild' in online communities: Reddit's resistance to SOPA," First Monday, vol. 19, no. 2, Feb. 2014.

[62] S. J. Kwon, E. Park, and K. J. Kim, "What drives successful social networking services? A comparative analysis of user acceptance of Facebook and Twitter," Soc. Sci. J., vol. 51, no. 4, pp. 534-544, Dec. 2014.

[63] C. Shane-Simpson, A. Manago, N. Gaggi, and K. Gillespie-Lynch, "Why do college students prefer
Facebook, Twitter, or Instagram? Site affordances, tensions between privacy and self-expression, and implications for social capital," Comput. Hum. Behav., vol. 86, pp. 276-288, Sep. 2018.

[64] H. Kwak, C. Lee, H. Park, and S. Moon, "What is Twitter, a Social Network or a News Media?," in Proceedings of the 19th International Conference on World Wide Web, New York, NY, USA, 2010, pp. 591-600. 